International Journal of Instruction e-ISSN: 1308-1470 • www.e-iji.net
July $2020 \bullet$ Vol.13, No.3

p-ISSN: 1694-609X

pp. $745-760$

Received: $19 / 05 / 2019$

Revision: 01/03/2020

Accepted: 06/03/2020

OnlineFirst: 19/05/2020

\title{
Indirect Specialized Vocabulary Learning and Learner Autonomy
}

\author{
Elham Ghobain
}

Jazan University, Saudi Arabia, eghobain@jazanu.edu.sa

\begin{abstract}
This research paper seeks to determine learner autonomy level in relation to incidental vocabulary acquisition (IVA), out of the realization of both concepts as prominent factors in language learning in general, and English for Specific Purposes (ESP) in particular. The paper particularly aims at examining the influence of participants', medical and applied medical sciences students, selflearning for specialized vocabulary on their autonomy levels. It assumes that leaving the task of acquiring specialized vocabulary to learners' endeavors, completely, leads to a positive effect on their autonomy levels. Participant autonomy levels were self-assessed through pretest and posttest quantitative surveys. The survey items aimed at assessing the participants' learning levels according to two categories of dependency and independency. The quantitative data was analyzed using SPSS to generate descriptive data. The overall results were generated through computing mean scores for each category of items at both phases, i.e. pretest and posttest. No significant differences between the two categories' data were indicated. Yet, a positive change occurred to the independency category in comparison to that of dependency, which remained somehow static through the period of the study. Although the results of this latter category indicated the learners' need for teacher guidance regarding the specialized vocabulary, the change in the first category should not be ignored. That is, IVA can be a positive agent in fostering learners' control of their learning, namely, autonomy. Simultaneously, since the results of both categories are somehow convergent, both approaches of explicit and implicit instructions should be considered in IVS approaches in the realm of ESP.
\end{abstract}

Keywords: learner autonomy, specialized vocabulary acquisition, implicit learning, incidental vocabulary acquisition, ESP

\section{INTRODUCTION}

In the context of the study, a medical complex at a Saudi university, decision makers at that context decided to leave the responsibility of learning and acquiring medical terms entirely to students. That is, they removed the element of teaching medical terminology (MT) from syllabus, hence, students must find their own ways of acquiring the terms. Apparently, this decision derived from a belief in implicit term acquisition, a term that 
encompasses IVA, through studying the content of students' majors. Indeed, leaving the entire process of learning the terms or specialized vocabulary to students requires a full responsibility from the students' side. To put it differently, implicit acquisition for certain vocabulary in ESP domains, especially in the medical field, might not be a straightforward process. MT may not be easy to grasp or acquire. Hence, some effort by learners, which should stem from their sense of responsibility, or simply autonomy, is needed. Accordingly, the current study assumes that students' attempts to learn specialized terms, through the content of their academic study, should lead to increased autonomy levels. There is a consensus about Asian learners in general, and Arab learners in particular, that they usually lack satisfying levels of autonomy; which is undoubtedly needed to help them proceed in their journey of learning the language. Thus, adopting such an approach of acquiring specialized vocabulary incidentally is questionable, and needs to be investigated.

To put it more clearly, in this project, autonomy is linked with contextualized terms acquisition, based on the belief that reading or studying textbooks are considered effective agents in both fostering autonomy in learning, and developing vocabulary (e.g. Krashen, 2004; Kaur, 2013; Carrell \& Carson, 1997; Agustín-Llach \& Alonso, 2017; Herrel \& Jordan, 2004).

According to Ellis (1994), Sockett and Toffoli (2012) and Rieder (2003), incidental learning is a key factor in vocabulary acquisition. It may be coterminous with implicit learning (Rieder, 2003:26), which can be situated in the realm of learner autonomy (LA) (Sockett and Toffoli, 2012). Schilhab (2007) highlights that implicit learning, pushed by internal incentive, is an authentic approach, closely relates the referent and its meaning, leading to one's natural learning and acquisition at his/her own pace. She indicates that implicit learning is of autonomic nature, as it leads to personal elucidation and individual understanding of meaning. This clearly states the link between the two psychological constructs of autonomy and incidental learning.

Indeed, the relationship between these constructs has long been established by relevant research. This relationship can otherwise become clearer with reference to the negative relationship between explicit instruction and autonomy. As Talley and Ling (2014) argue, explicit instruction becomes reduced with higher level of autonomy from learners' side, which in its turn indicates harmony between autonomy and implicit learning. Therefore, the current study assumes learners' increased autonomy through an implicit approach for acquiring medical terms.

\section{LITERATURE REVIEW}

\section{Learners' Autonomy and Incidental Term Acquisition}

New vocabulary incidental acquisition through reading or listening, for first, second, and foreign language learners or speakers, has been indicated and supported by ample research in the literature (e.g. Krashen, 1989,; Krashen, 2004; Paribakht and Wesche 1993, 1999; Nagy and Scott, 2000; Feng, 2017; Ellis, 2004). This process of vocabulary acquisition can be referred to as, or is encompassed in, indirect, implicit vocabulary learning (Rieder, 2003). When applying the same principle to specialized vocabulary or 
technical terms learning, as in the case of ESP, similarly, some kind of responsibility by students, is required. This kind of responsibility is a direct reference to LA.

Learner Autonomy has become a crucial construct of learning, with a particular significance in learning languages or language acquisition. Holec (1981), the pioneering scholar in this area since the early 1980s, defines LA as the responsibility that should be taken by individuals for their own learning. A simple interpretation of LA can be the learner involvement in the content of his/ her own learning, rather than the knowledge being merely transmitted from teachers (Surma, 2004). LA is also defined as, or usually interchangeable with, learner's independent learning (Dickinson, 1992). An independent learner uses, or is trained to use, language learning strategies in the process of learning a language.

Phil Benson, who did several studies in the area of autonomy, (e.g. 1996, 2001, 2006), emphasizes that when learners are in charge of their own learning, or realize their responsibility for their learning, they can develop their own strategies for acquiring knowledge.

It has been argued extensively that the concept of autonomy is a western value, which is not observable in Eastern or Asian countries, where teachers are often still the center of learning and teaching. As Littlewood (1999) stated, Asian learners appreciate and esteem teacher-led learning. Ceylan's (2015) study on Turkish learners confirms Littlewood's assertion. While investigating strategies that may help foster learners' autonomy, Ceylan (ibid.) found that participants revealed some expectations that affected their perception of responsibility. Although they can be considered somehow autonomous, they are still largely dependent on their teachers.

Therefore, several studies have been conducted in Asian contexts, the findings of which, however, are still inconclusive (Littlewood,1999). Abadi and Baradaran (2013) examined the relationship between vocabulary acquisition and autonomy amongst Iranian learners, and found a positive significant relationship between the two constructs. In the context of Saudi Arabia (SA), the context of this upcoming study, few studies on learners' autonomy, particularly readiness for taking responsibility for independent or autonomous learning, were conducted. Generally, it can be said that through a breadth of studies, Saudi learners are said to reveal low to moderate learning autonomy levels (Borg and Alshumaimeri, 2017; Alrabai, 2018). Tamer's (2013) study investigated first-year male university students' perceptions of responsibility and involvement in autonomous learning activities. It found that learners were reluctant to take responsibility for their own learning, and were highly dependent on their teachers, regardless of their high motivations levels. Similarly, Alrabai (2017a) and Alzubi, Singh, and Pandian (2017) confirmed the Saudi students' teacher dependency, and low levels of learning responsibility and readiness for independent learning. However, Almusharraf (2019) investigated female university students' attitudes towards implementing autonomous vocabulary learning methods. The participants revealed realization for those methods and strategies in developing their sense of responsibility. 
If the concept of LA is recognized as a prominent and effective agent in learning in general and acquiring languages in particular, it is as such or more in terms of IVA or implicit learning. Indeed, there is an established relationship between implicit learning and LA. That can become plausible especially with the abundant resources available nowadays for students in the media, besides their social networking in virtual communities. However, Sockett and Toffoli (2012) seem to distinguish between LA construct and social networking as a natural resource through which language can incidentally be acquired. They argue that social networking, including the informal and incidental learning it entails, is replacing the concept of LA as a planned activity. According to them, the construct of autonomy was created when there was no direct contact with English. They suggest that incidental or informal learning is a better approach to describe their learners. Those learners are engaged in independent language use, away from any institutional arrangement, due to their frequent contact with the language in formal and informal settings that are relating to their major fields of study and their leisure activities.

Nevertheless, latest literature in the area of language acquisition still emphasizes the role of implicit learning in boosting the development of learners' autonomous language learning habits (Nazari, 2014). According to Doughty \& Williams (1998) and Nazari (2014), the practices of recognizing and noticing patterns, forms and meanings through authentic learning situations represent autonomous learning instances. That is, implicit learning or acquisition itself is recognized as an autonomous process (ibid.)

Constituting the most essential and crucial part of language acquisition, to the extent of being a feature of judging proficiency (Laufer \& Hulstijn, 2001) vocabulary, its acquisitions and processes, has and is being extensively researched, especially by researchers interested in reading development (Nagy and Scott, 2000). Nagy and Scott (ibid.) justify that claim by the established recognition of the influence of vocabulary on reading comprehension. However, they also highlight the varied or low interest in vocabulary research among other practitioners, by indicating that it figures at the bottom of their interest list, mainly due to current emphasis on authentic and integrated instruction. This in itself highlights the more recent, top-down fashion, emphasis on metalinguistic skills, and leaning for incidental language acquisition in modern pedagogy. The importance put to reading as a resource of acquiring language or vocabulary apparently stems from a belief in incidental learning. That is, these two aspects are always concomitant. Barcroft's (2009:85) explanation of the process confirms that through a direct reference to free reading as an example of incidental vocabulary learning. He explains that incidental vocabulary learning occurs when learners acquire new words from context without an intention to do so as in the case of picking up new words unintentionally during free reading. Similarly, Collins (2010) refers to frequency of home reading as a significant and positive agent of vocabulary acquisition; due to frequent exposure to target vocabulary through frequent reading practices.

That said, Nagy and Scott (2000) refer to immersion in vocabulary-rich contexts that comprise, besides reading, abundant oral and written inputs of language, as elements of 
vocabulary growth. They also indicate that through such situations, learners find the process of acquiring vocabulary, by no means, occurring automatically. In other words, learners need some understanding about the contexts in which they operate, in order to be active and independent while growing their vocabulary, so they become able to produce usable words, unlike the case when they memorize glossary of synonyms and definitions.

The above review on the link between free reading and vocabulary acquisition establishes the relationship between incidental vocabulary acquisition and autonomy, recognizing that home reading needs a good level of independent learning styles. Thus, the situation approached by the upcoming study represents a case of that review, taking for granted the oral and written inputs through classes, besides intendent free or home reading necessary for achieving success in the major field.

\section{Research Aims, Objectives and Questions}

The current study attempts to examine participants' degree of autonomy, assuming that the task of implicit learning requires a responsible and independent learning style. The study will also experiment participant autonomy levels and terms acquisition after spending a period of time immersed in this approach. That is, the study aims at investigating whether autonomy can be fostered over the period of study, through participants' assumed responsibility for learning terms.

The study seeks to achieve these objectives through addressing the following questions:

1- What autonomy levels, based on dependent and independent learning levels, do participants in this study reveal?

2- Is there a significant change in participants' autonomy levels during the time frame of the study?

\section{METHOD}

The descriptive and partially experimental nature of the study and its main purpose make it a good fit into the quantitative approach, as it aims at identifying a cause and effect relationship between two constructs, namely, IVA and autonomy. According to Williams (2007), descriptive quantitative approach is a basic research method that examines the current state of a situation. It identifies attributes of a phenomenon according to observation or exploration of correlated phenomena. The study is also partially experimental as it investigates the treatment of an intervention (incidental learning of MT) into the study group, measuring the outcomes of that treatment (Leedy and Ormrod, 2001). It adopts a longitudinal developmental design, through which the researcher tries to understand the influence of the intervention on the study group, by surveying their learning dependency and independency levels during the study span. The targeted study group constitutes prospective medical students, namely first-year university students majoring in medical fields (refer to table 2)

The data in this paper is part of a larger project on IVA, which uses an online questionnaire as its primary tool. The items of this questionnaire that will appear in the 
current paper are related to the participants' biographical data, including their selfassessed proficiency levels, and their self-evaluated autonomy. These items are adapted from a Learner Autonomy Questionnaire (LAQ) that was first developed and used by Egel (2003) and/ or Savaskan (2003) ${ }^{1}$ in the Turkish context. The original questionnaire includes 44 items organized according to nine dimensions that assess the degree of learners' control on their learning (Gholami, 2013; 2016; Savaskan, 2017). LAQ is reported score .80 Cronbach Alpha (Gholami, 2013; 2016 and Savaskan, 2017) i.e. above 0.7 which makes it sufficiently reliable (George and Mallery, 2003).

For the purpose of the study at hand, only the first four, out of the nine, dimensions are adopted: Readiness for Self-direction, Independent Work in Language Learning, Importance of Class/ Teacher, and Role of Teacher: Explanation/ Supervision, primarily aiming at identifying the learner's dependency and independency in terms of their learning. Being part of a larger project, only 9 items are adapted for assessing these four dimensions; one for the first, three for the second and third each, and two for the fourth. This arrangement or adaptation is not arbitrary, it comes as an attempt to be more relevant to the participants' behaviours and understanding, and also to the scope of the project.

The items can also be classified into two categories: four items under the "dependent learner" category and five under "independent learner" category. Needless to say, the increase in the first set, and the decrease in the second, indicate a high LA level. The following table attempts to describe the items used along with their categories based on both types of classification:

Table 1

Items Adapted from LAQ for the Purpose of the Upcoming Study

\begin{tabular}{|c|c|c|}
\hline Dimension & Items & $\begin{array}{l}\text { Independent/D } \\
\text { ependent }\end{array}$ \\
\hline $\begin{array}{l}\text { Readiness for } \\
\text { Self-direction }\end{array}$ & I usually set my own goal for each semester & Independent \\
\hline \multirow{3}{*}{$\begin{array}{l}\text { Work in } \\
\text { Language } \\
\text { Learning }\end{array}$} & While learning English, I like activities in which I can learn on my own & Independent \\
\hline & I use my own methods to learn vocabulary in English & Independent \\
\hline & I think that I learn English better when I work on my own & Independent \\
\hline \multirow{3}{*}{$\begin{array}{l}\text { Importance of } \\
\text { Class/ Teacher }\end{array}$} & My teacher always has to guide me in learning English & Dependent \\
\hline & I can learn English only with the help of my teacher & Dependent \\
\hline & I can learn the English grammar on my own/ without needing a teacher & Independent \\
\hline \multirow{2}{*}{$\begin{array}{l}\text { Role of } \\
\text { Teacher: } \\
\text { Explanation/Su } \\
\text { pervision }\end{array}$} & I want the teacher to give us the words that we are to learn & Dependent \\
\hline & I learn better when the teacher explains something on the board & Dependent \\
\hline
\end{tabular}

Constituting a part of a broader project, the survey items in this paper were sent to two expert colleague researchers working at the English Language Institute that belongs to

\footnotetext{
${ }^{1}$ The researcher attempted her best to determine who first designed and used the LAQ. two resources (Gholami 2013; 2016) claim it belongs to a PhD thesis by Egel (2003), while Savaskan (2017) claims that it was first developed and adopted by Savaskan (2003) in her PhD thesis.
} 
the targeted organization, after being translated from English to Arabic, asking them for their feedback and back-translation. They were asked to fill in the forms and give their instant feedback.

Away from the context of the study, the LAQ itself was validated through several previous studies and researchers, all conducted in Asian ELF contexts, starting from Savaskan (2003) and Egel (2003), who were followed by Gholami (2013; 2016), Tilfarlioglu and Ciftci (2011); Gömleksiz, and Bozpolat (2012); Karagöl (2008), (cited in Gholami, 2016). Thus, face, content, and construct validity can be claimed.

The first page of the questionnaire contains information about the study and data protection policy at the institution, informing the participants about the permit granted to the researcher to conduct the study, and asking the participants for their consent.

The situation of learning MT implicitly, without any designed explicit instruction, and leaving the entire task of learning for students to acquire those MT either through oral or written inputs, i.e. lectures and reading textbooks, represents the scope of the study. The designed questionnaire was administered twice, pretest and posttest, at the beginning of the first and second academic semesters, during a period of three months. The two surveys, pretest and posttest, targeted the same group of participants, namely, first-year university students who are majored in medical fields. The sampling was randomized in the sense that it was not guaranteed that participants of the first test had participated in the second one. However, the returned number of responses indicated that the majority of the total number of that academic batch participated in the study.

The survey was administered through the Google docs service, and analyzed with IBM SPSS version 23, after being exported and coded into a Microsoft Excel spreadsheet. Web-based or electronic surveys appear to have begun to replace postal surveys. The practicality, cost effectiveness, feasibility, and speed of distribution are among the most prominent features that can be achieved through online or electronic surveys. This kind of surveys enables researchers to automatically verify, store and transfer responses into a database (Andrews Nonnecke and Preece, 2003). The study employs one data collection tool due to a lack of feasibility in reaching subjects several times, bearing in mind their busy schedules and study loads rendered by the medical field. Andrews et al. (ibid) identifies the difficulty of accessing such participants as a reason for adopting only one data collection tool.

\section{FINDINGS}

The analysis aimed to generate descriptive data through frequencies in terms of participants' biographical data. The questionnaire items assessing participants' proficiency and the construct of autonomy were introduced on a 5-point scale. Responses to these items were statistically analyzed to calculate Mean, Standard Deviation, Mode, and Median for each item. The following presents, firstly, the demographics of the participants, followed by items assessing their independency, and lastly, items assessing their dependency in learning. Increases in numeric of the first category, independent learning, are considered positive, whereas any increase in the 
second category, i.e. dependent learning, is considered negative in terms of participants' autonomy levels.

\section{Participants' Demographics}

Table 2

Participants' Demographics

\begin{tabular}{|c|c|c|c|c|c|c|}
\hline & \multicolumn{3}{|l|}{ Pre-test Survey } & \multicolumn{3}{|l|}{ Post-test Survey } \\
\hline Sample Size & $\mathrm{N}=114$ & & & $\mathrm{~N}=95$ & & \\
\hline \multirow{2}{*}{ Program } & Medicine & AMS & & Medicine & & AMS \\
\hline & $63=55.3 \%$ & $51=44.7$ & & $54=56.8 \%$ & & $41=43.2 \%$ \\
\hline \multirow[t]{2}{*}{ Gender } & Female & Male & & Female & & Male \\
\hline & $72=63.2 \%$ & $42=36.8$ & & $42=44.2 \%$ & & $53=55.8 \%$ \\
\hline \multirow{2}{*}{$\begin{array}{l}\text { Self-assessed } \\
\text { proficiency }\end{array}$} & Mean $\quad$ SD & Median & Mode & Mean $\quad$ SD & Median & Mode \\
\hline & 3.36 & 3.00 & 3 & 3.82 & 4.00 & 3 \\
\hline
\end{tabular}

The sample size, as shown in table 2, consists of 114 students in the pretest survey. The participants in this phase belong to the medical college (55\%), and faculty of applied medical sciences (AMS) (44\%). Female students comprise $63 \%$ of this phase respondents. The post-test survey included 95 students from the same colleges, with comparatively similar demographics, i.e. 56\% from the medical college and $43 \%$ from AMS college. Male participants constitute 55\% out of this latter survey. The participants evaluated their proficiency at point 3 based on the median and mode analysis in the first pretest survey, with $\mathrm{M}=3.36 \mathrm{SD}=1.19$. In the post-test survey, the median increased to reach 4 , mode remained the same at 3 , and mean slightly rose to $\mathrm{M}=3.82 \mathrm{SD}=.91$

\section{Independent Learning Assessment}

The degree of learners' independency or control of their learning was self-assessed through responding to the five statements presented in the following table. The data analysis is presented in five columns to indicate the phase and the descriptive statistical analysis of median, mode, mean and standard deviation. Horizontally, the table shows ten rows, as responses gathered from both pretest and posttest surveys, are shown alongside each statement.

Table 3

Participants' Independent Learning Assessment at Both Phases: Pretest and Posttest

\begin{tabular}{|c|c|c|c|c|}
\hline \multirow{3}{*}{ a-I usually set my own goals at the beginning of every semester } & phí Median & Mode & Mean & SD \\
\hline & pre 3.00 & 3.00 & 3.06 & 1.26 \\
\hline & pos 3.00 & 3.00 & 3.12 & 1.32 \\
\hline \multirow{2}{*}{$\begin{array}{l}\text { c-While learning English, I enjoy the activities through which } \\
\text { learn on my own }\end{array}$} & pre 3.00 & 5.00 & 3.43 & 1.35 \\
\hline & pos 4.00 & 5.00 & 3.57 & 1.34 \\
\hline \multirow[t]{2}{*}{ e-I use my own strategies for learning vocabulary } & pre 4.00 & 5.00 & 3.72 & 1.18 \\
\hline & pos 4.00 & 3.00 & 3.86 & 1.14 \\
\hline \multirow[t]{2}{*}{ g-I can learn grammar by myself. I don't need a teacher for that } & pre 3.00 & 3.00 & 2.86 & 1.32 \\
\hline & pos 5.00 & 5.00 & 2.92 & 1.35 \\
\hline \multirow[t]{2}{*}{ i-I think I learn English better when I learn alone } & pre 4.00 & 5.00 & 3.44 & 1.31 \\
\hline & pos 4.00 & 4.00 & 3.56 & 1.25 \\
\hline
\end{tabular}


As shown in table 3, the participants revealed a moderate, acceptable level of independent learning, ranging from $\mathrm{M}=2.86 \mathrm{SD}=1.32$ to $\mathrm{M}=3.72 \mathrm{SD}=1.18$ during the pretest, in statements $g$ and e. The participants' highest level of independent learning is related to strategies of learning vocabulary, with median 4 at both phases, as shown in statement e, whereas the lowest level is linked with learning grammar as indicated in statement $\mathrm{g}$. However, there is a positive change in all the statistics of this latter statement, Median and Mode from 3 to 5, and Mean from 2.86 to 2.96 through the period between the pretest and posttest.

Overall, besides statement $\mathrm{g}$, an increase, although slight, across all statements is indicated in the post-test survey, including the mean of statement e $\mathrm{M}=3.86 \mathrm{SD}=1.14$. That is, the highest level of autonomy, as indicated in statement e post-test, is associated with learning vocabulary. However, if we look at the median analysis across the five statements, the numbers almost remain static, except for statement c and g, from 3 to 4 , and 3 to 5, respectively. Thus, it can be said that the participants' levels of autonomous or independent learning moderately increased during the span of the study.

\section{Dependent Learning Assessment}

Unlike the analysis of the previous part, any increase in the analysis numeric during the study, in terms of the following section of dependent learning, is considered negative. In other words, smaller numbers indicate good level of independency in learners' learning.

Table 4

Participants' Dependent Learning Assessment at Both Phases: Pretest and Posttest

\begin{tabular}{|c|c|c|c|c|c|}
\hline \multirow{3}{*}{$\begin{array}{l}\text { b-I learn better when the teacher explains the details on the } \\
\text { board }\end{array}$} & phase & Median & Mode & Mean & SD \\
\hline & pre & 4.00 & 5.00 & 3.47 & 1.32 \\
\hline & post & 4.00 & 5.00 & 3.58 & 1.30 \\
\hline \multirow[t]{2}{*}{ d-I can learn English only with the help of a teacher } & pre & 2.00 & 1.00 & 2.10 & 1.17 \\
\hline & post & 2.00 & 1.00 & 2.11 & 1.20 \\
\hline \multirow{2}{*}{$\begin{array}{l}\text { f-My teacher should guide and instruct me while learning } \\
\text { English }\end{array}$} & pre & 4.00 & 4.00 & 3.45 & 1.21 \\
\hline & post & 3.00 & 3.00 & 3.50 & 1.21 \\
\hline \multirow{2}{*}{$\begin{array}{l}\text { h-I want the teacher to give me the list of words I have to } \\
\text { study }\end{array}$} & pre & 5.00 & 5.00 & 4.13 & 1.18 \\
\hline & post & 4.00 & 5.00 & 4.12 & 1.24 \\
\hline
\end{tabular}

Interestingly, the participants also revealed comparatively similar results regarding dependent learning through statements in table 4. That is, the learners' dependency levels are considered mediocre in general, except for statement $\mathrm{d}$ and $\mathrm{h}$, which reveal clear positive and negative results, respectively. That is, the high results of statement $h$, with a very slight decrease in means analysis though, i.e. from $M=4.13$ to $M=4.12$ through both surveys, indicate the participants' dependency on teachers, and particularly in learning vocabulary. In fact, data of all the other statements, except $d$, asserts the same stance, with even a slight increase, instead of decrease, through the post-test survey, which indicate a negative stance in terms of learners' autonomy. Even analysis of statement $d$, although is generally considered positive, shows an increase in the posttest survey instead of decrease. 


\section{Dependent and Independent Learning Combined}

If we look at mean analyses of the most relevant statements to the scope of the study, i.e. items $\mathrm{e}$ and $\mathrm{h}$ that are relating to learning vocabulary, both dependently and independently, the situation becomes rather confusing. The results of statement $\mathrm{e}$ in the independent learning category is considered above the middle (pretest $\mathrm{M}=3.72$ $\mathrm{SD}=1.18$, and postest $\mathrm{M}=3.86 \mathrm{SD}=1.14$ ), i.e. approaching point 4 in the scale, which is considered positive in this case. On the other hand, data of statement $h$, which is clearly high, i.e. (Pretest $\mathrm{M}=4.13 \mathrm{SD}=1.18$ and $\mathrm{M}=4.12 \mathrm{SD}=1.24$ posttest) is considered negative as it refers to the degree of learners' dependency on teacher.

In general, both categories, dependent and independent learning, do not reveal considerable differences across the two tests. In other words, there is a difference in students' autonomy level through the period of the study, yet it is not dramatic. That said, if we consider the median values across the two categories of items, a positive change can be detected through certain item analyses. More specifically, the increase in median values in statements $\mathrm{c}$ and $\mathrm{g}$ in table 3 , which assesses the independent learning, from 3 to 4 and 3 to 5 through the pretest and posttest periods, respectively, is a positive change. Similarly, the decrease in the second category median values, particularly in statements $\mathrm{f}$ and $\mathrm{h}$, from 4 to 3 and 5 to 4 , respectively, is also a positive change, indicating that learners' dependency has decreased, even though slightly.

Overall, comparing the means of both sets of statements in tables 3 and 4, it becomes obvious that dependent learning statements are comparatively higher than independent learning statements. Computing the mean scores at both phases, participants reveal equal levels of dependency and independency in the pretest survey, $(\mathrm{M}=3.29 \mathrm{SD}=.80$ and $\mathrm{M}=3.30 \mathrm{SD}=.85)$, and more independency $(\mathrm{M}=3.41 \mathrm{SD}=.82)$ than dependency $(\mathrm{M}=3.33$ $\mathrm{SD}=.84$ ) in the post-test survey.

Table 5

Mean Score Computed for Participants' Independent and Dependent Learning at Both Pretest and Posttest Surveys

\begin{tabular}{lll}
\hline Phase & Independency & Dependency \\
\hline Pre-test Survey & $\mathrm{M}=3.30 \mathrm{SD}=.85$ & $\mathrm{M}=3.29 \mathrm{SD}=.80$ \\
\hline Post-test Survey & $\mathrm{M}=3.41 \mathrm{SD}=.82$ & $\mathrm{M}=3.33 \mathrm{SD}=.84$ \\
\hline
\end{tabular}

Through the study, as shown in table 5, it is clear that learners' independency slightly increased from $\mathrm{M}=3.30 \mathrm{SD}=.85$ to $\mathrm{M}=3.41 \mathrm{SD}=.82$. However, although the increase in dependency level from $\mathrm{M}=3.29 \mathrm{SD}=.80$ to $\mathrm{M}=3.33 \mathrm{SD}=.84$ is slight, yet it is still considered negative. Since the mean scores of both groups are comparatively similar, the judgment on the students' control of their learning becomes complicated.

\section{DISCUSSION}

The study assumed that, through the process of independently acquiring and learning MT, participants' independent learning and autonomy levels would be promoted. Based on the analysis of and comparison between the means of both learner dependency and independency levels at the beginning of the study, it can be said that, participants in this 
study are moderately autonomous (refer to table 5). This finding confirms previous studies by Borg and Alshumaimeri (2017) and Alrabai (2018) in terms of Saudi learners low or moderate autonomy and independency levels. The finding of statement $f$ particularly supports Littlewood's (1999) assertion, which has been further asserted by Ceylan's (2015) findings on Asian, Middle-eastern, learners' dependency on teachers and appreciation for teacher-led learning. In other words, the findings contribute to Ceylan's (2015) study in the sense that participants in this study: (1) are similar to Turkish participants being Asian or Middle-eastern, (2) are considered relatively autonomous, (2) and simultaneously still dependent on their teachers. The same point is further reflected through item $h$, which reveals learners' high level of dependency on teachers. Thus, these findings also contribute to Tamer (2013), Alrabai (2017a), and Alzubi's et al. (2017) studies in concluding the Saudi learners' teacher dependency, and consequently low responsibility levels towards learning the language. Previous studies in the field of autonomy, on the Saudi context, as reviewed and concluded by Alrabai (2017b) and Asiri and Shukri (2018), indicate that the cultural aspect of teachers being the main transporter of knowledge and the primary figure of authority is a significant factor influencing the learners' dependency (e.g. Ho and Crookall, 1995)

Nevertheless, literature, such as Tamer (2013), Alrabai (2017a), Alrabai (2017b) and Alzubi's et al. (2017) studies, also indicated Saudi learners' readiness for independent learning, which is also validated through the current study. The overall revealed findings on learners' independency is likewise moderate and acceptable. Such findings, however, should be encouraging to work on enhancing Saudi learners' readiness to reach satisfying levels of learning independency. This should not be surprising in the $21^{\text {st }}$ century, which has endowed the new generations with various skills that help nourishing learners' autonomous attributes. This situation might also have resulted from the constant educational reforms undertaken by Saudi educational authorities.

In relation to the treatment adopted in the current study, the participants' independency readiness either increased or remained at the same moderate levels during the study period, i.e. across the two phases of the study. This stands as a core finding of this project. Looking at table 5, learners' overall independency level has increased by $11 \%$ in comparison to their overall dependency level, which also increased yet by only $4 \%$. Thus, it can be said, the treatment of the current study has positively influenced the participants' independency level, yet to a limited extent, bearing in mind the slight increase in their dependency level as well. A closer look at each statement in both sets of items also approves the overall findings, as most of the independency items reveal an increase in the level, more than it can be said to the dependency items. That said, the proximity of results rates of each set of items well fits in Littlewood's (1999) argument and Ceylan's (2015) findings on the difficulty of fostering autonomy for Asian learners. The even situation can also be indicative of the gradual transitional period from the traditional classroom to that which is influenced by the $21^{\text {st }}$ century attributes. According Little (1995), students who are not used to learning independently find it difficult to accept such 'new' or 'different' learning style. 
That said, the positive effect that occurred to participants' independency level, besides approving previous studies on Saudi learners' readiness for taking responsibilities of learning the language (e.g. Tamer, 2013; Alrabai, 2017a; Alzubi's et al., 2017), is also matched with Almusharraf's (2019) study. Almusharraf (ibid.) found an increase in participants' autonomy level through implementing autonomous vocabulary learning methods. This latter study indicated that the learners' sense of responsibility had positively developed through certain autonomous vocabulary strategies, which can be applicable to the treatment adopted in the current study. In general, these findings are suggestive of possible positive changes to the Saudi learners' learning styles if they are equipped with needful skills. According to Benson (2011), learners in teacher-centred classroom need training that prepare their psychological readiness for learner-centred approaches. In fact, not only learners, teachers in such context also need to be wellprepared in order to be able to help their learners adapt to self-learning and autonomous strategies.

Generally, due to the increased level of the participants' learning independency level, which in its turn should be resulting from being at an implicit leaning milieu as assumed by many researchers (e.g. Collins, 2010), the study contributes to those studies that consider the positive relationship between IVA and autonomy, such as Doughty \& Williams (1998), Nazari (2014), and Nagy \& Scott (2000).

\section{CONCLUSION}

The study expected growth in the students' level of autonomy, assuming that they were to adapt to the independent learning style, which require them to take responsibility and be committed over a longer period of learning. It is concluded from the analysis, considering independent learning at both stages, that a change did occur. However, this change is not strongly significant due to comparatively equally expressed learners' dependency.

That said, in comparison to research conducted in the context of Saudi Arabia, this study indicates an overall growth in learner independency, i.e. autonomy, through the period during which they had to learn MT or specialized vocabulary incidentally. This revealed increase in learners' independency should forward and direct the attention to IVA as a positive approach in the fields of ESP and English as a Medium of Instruction.

Indeed, if the data on independent learning is taken exclusively, the levels revealed show a satisfactory level of autonomy. In other words, the overall revealed moderate independency level of the participants in itself indicates a progress in such learners' autonomy, which has always been stereotyped in previous studies as low.

However, this finding is still not conclusive, bearing in mind the limitations of the study. The sample of the study might not be a true and inclusive representative of Saudi learners, as they are medical, hence ESP, students, who have certain specific and distinctive characteristics. It is believed that these learners are usually under significant stress due to heavy academic loads and busy schedules. Therefore, documenting their learning strategies for learning specialized vocabulary when it is not directly taught is recommended. Learners in such situation usually pay attention to other disciplinary 
subjects at the expense of learning English. Besides, consideration must be given to the period during which the study is conducted, which included tests of other subjects. It is recommended to replicate the study while considering the element of time, allowing for more experiment period, with two groups, control and experiment. The researcher acknowledges the limitation of using one tool, and the use of a mono-method approach being merely quantitative. However, the study justifies these limitations given the nature of medical students, and the challenges of conducting research with such a sample.

Additionally, it can be concluded that the fixed levels of most of the dependency scales over the period of the study suggest the students' need for some direct instruction for MT. Thus, educators may consider blended or mixed instructional methods that combine both direct and indirect approaches of teaching and learning specialized vocabulary. Concomitantly, and in order to delve in the reasons behind static scales of the expressed learning dependency, a qualitative method should be implied.

To sum up, IVA as an approach has positively influenced participants' independency, yet only slightly. Therefore, despite the spotted growth in the participants' independency level, the data in the study, cannot decisively define degrees of revealed LA in its context, due to moderate, though static, dependency levels.

\section{REFERENCES}

Abadi, E. A. \& Baradaran, A. (2013). The relationship between learner autonomy and vocabulary learning strategies in Iranian EFL learners with different language proficiency level. International Journal of Applied Linguistics \& English Literature, 2/3, 176-185. https://doi.org/10.7575/aiac.ijalel.v.2n.3p.176

Agustín-Llach, M.P. \& Alonso, C. A. (2017). Fostering Learner Autonomy Through Vocabulary Strategy Training, in Pawlak M. et al. (eds.), Autonomy in Second Language Learning: Managing the Resources. Second Language Learning and Teaching, Springer.

Almusharraf, N. (2019). Learner autonomy and vocabulary development for Saudi university female EFL learners: Students' perspectives. International Journal of Linguistics, 11/1, 166-195

Alzubi, F., Singh, M., and Pandian, A. (2017). The use of learner autonomy in English as a foreign language context among Saudi undergraduates enrolled in preparatory year deanship at Najran University. Advances in Language and Literary Studies, 8/2, 152160

Alrabai, F. (2018). Learning English in Saudi Arabia, In Ch. Moskovsky \& M. Picard (Eds.) English as a Foreign Language in Saudi Arabia, 102- 119, $1^{\text {st }}$ Edition. Routledge.

Alrabai, F. (2017a). From teacher dependency to learner independence: a study of Saudi learners' readiness for autonomous learning of English as a Foreign Language. Learning and Teaching in Higher Education: Gulf Perspectives, 14/1. http://doi.org/10.18538/lthe.v14.n1.262 
Alrabai, F. (2017b). Exploring the Unknown: The Autonomy of Saudi EFL Learners. English Language Teaching, 10/5, 222-233

Andrews, D., Nonnecke, B., and Preece, J. (2003). Electronic survey methodology: A case study in reaching hard to involve Internet Users. International Journal of HumanComputer Interaction, 16/2, 185-210

Asiri, J. \& Shukri, N. (2018) Female Teachers' Perspectives of Learner Autonomy in the Saudi Context. Theory and Practice in Language Studies, 8/6, 570-579.

Barcroft, J. (2009). Effects of synonym generation on incidental and intentional L2 vocabulary learning during reading. TESOL Quarterly, 43/1, 79-103.

Benson, P. (1996). Concept of autonomy in language learning. In R. Pemberton, E. S. L. Li, W. W. F. Or, \& H. D. Pierson (Eds.), Taking control: Autonomy in language learning, 27-34. Hong Kong, China: Hong Kong University Press.

Benson, P. (2001). Teaching and researching autonomy in language learning. London, England: Pearson Education.

Benson, P. (2006). Autonomy in language teaching and learning. Language Teaching, $40,21-40$

Borg, S. and Alshumaimeri, Y. (2017). Language learner autonomy in a tertiary context: Teachers' beliefs and practices. Language Teaching Research, 23/1, 9-38

Carrell, P. \& Carson, J. G.(1997). Extensive and intensive reading in an EAP setting. English for Specific Purpose, 16, 47-60.

Ceylan, N. (2015). Fostering learner autonomy. GlobELT: An International Conference on Teaching and Learning English as an Additional Language. Social and Behavioral Sciences, 85-93

Collins, M. F. (2010). ELL preschoolers' English vocabulary acquisition from storybook reading. Early Childhood Research Quarterly, 25, 84-97.

Doughty, C. and Williams, J. (1998) Focus on Form in Classroom Second Language

Acquisition. Cambridge: Cambridge University Press

Dickinson, L. (1992). Talking shop: Aspects of autonomous learning, An interview with Leslie Dickinson. ELT Journal, 47/1, 330-341.

Egel, İ. P. (2003). The impact of the European language portfolio on the learner autonomy of Turkish primary school students. Unpublished Doctoral Dissertation. Anadolu University, Eskişehir

ELLIS, R. (1994). Factors in the incidental acquisition of second language vocabulary from oral input: A review essay. Applied Language Learning, 5/1, 1-32.

Ellis, R. (2004). The definition and measurement of explicit knowledge. Language Learning, 54, 227-275 
Feng, Y. (2017). How does mode of input affect incidental vocabulary learning. Electronic Thesis and Dissertation Repository, 4794. https://ir.lib.uwo.ca/etd/4794

Gholami, H. (2016). Self Assessment and Learner Autonomy. Theory and Practice in Language Studies, 6/1, 46-51

George, D., \& Mallery, P. (2003). SPSS for Windows step by step: A simple guide and reference. 11.0 update (4th ed.). Boston: Allyn \& Bacon.

Herrell, A. \& Jordan, M. (2004). 50 strategies for teaching English language learners. Upper Saddle River, NJ: Pearson.

Ho, J., \& Crookall, D. (1995). Breaking with Chinese cultural traditions: learner autonomy in English language teaching. System , 2/23, 236-237.

Holec, H. (1981). Autonomy and foreign language learning. Oxford: Pergamon.

Kaur, N. (2013) The need for autonomous vocabulary learners in the Malaysian ESL classroom. GEMA Online ${ }^{\circledR}$ Journal of Language Studies, 13/3, 1675-8021

Krashen, S. (1989) We acquire vocabulary and spelling by reading: Additional evidence for the input hypothesis. Modern Language Journal, 73, 440-464.

Krashen, S. (2004). The power of reading: Insights from the research. Westport, CT: Libraries Unlimited.

Laufer, B., \& Hulstijn, J. (2001). Incidental vocabulary acquisition in a second language: The construct of task-induced involvement. Applied Linguistics, 22/1, 1-26.

Leedy, P. \& Ormrod, J. (2001) Practical Research: Planning and Design. 7th Edition, Merrill Prentice Hall and SAGE Publications, Upper Saddle River, NJ and Thousand Oaks, CA.

Little, D. (1995). Learning as Dialogue: The Dependence of Learner Autonomy on Teacher Autonomy. System, 23/2, 175-181

Littlewood, W. (1999). Defining and developing autonomy in East Asian contexts. Applied linguistics. 20/1, 71-94.

Nagy, W. E., \& Scott, J. A. (2000). Vocabulary processes. In M. L. Kamil, P. B. Mosenthal, P. D. Pearson, \& R. Barr (Eds.), Handbook of reading research, 3, 269284). Mahwah, NJ, US: Lawrence Erlbaum Associates Publishers.

Nazari, N. (2014). The impact of implicit tasks on improving the learners' writing in terms of autonomy and grammatical accuracy. International Journal of Instruction, 7/1, 121-134

Paribakht, T. S., \& Wesche, M. (1993). Reading comprehension and second language development in a comprehension-based ESL program. TESL Canada Journal, 11/1, 929. 
Paribakht, T. S., \& Wesche, M. (1999). Reading and "incidental" L2 vocabulary acquisition. Studies in Second Language Acquisition, 21/2, 195-224.

Ryan, G. (2010). Specialized vocabulary acquisition through texts in the theology classroom. Unpublished Ph.D. Thesis. Rosemead School of Psychology, Biola University

Rieder, A. (2003). Implicit and explicit learning in incidental vocabulary acquisition. Paper presented at the EUROSLA Conference, Edinburgh.

Schilhab, T. S. (2007). Knowledge for Real: On implicit and explicit representations and education. Scandinavian Journal of Educational Research, 51/3, 223238, DOI: $10.1080 / 00313830701356034$

Sockett, G. \& Toffoli, D. (2012) Beyond learner autonomy: A dynamic systems view of the informal learning of English in virtual online communities. ReCALL, Cambridge University Press (CUP), 24/2, 138-151

Surma, M. U. (2004). Autonomy in foreign language learning: An exploratory analysis of Japanese learners. Unpublished Thesis, University of ECU Australia Research Repository. Retrieved from https://ro.ecu.edu.au/theses/785

Talley, P.C. \& Hui-ling, T. (2014). Implicit and explicit teaching of English speaking in the EFL classroom. International Journal of Humanities and Social Science, 4-6

Tamer, O. (2013). Students' readiness for autonomous learning of English as a foreign language. Unpublished MA thesis, University of Sunderland, UK. Available online at http://awej.org/images/Theseanddissertation/OmerTamer/109thesis.pdf

Williams, C. (2007) Research Methods. Journal of Business \& Economic Research, 5, 65-72 